\title{
The Auditory Sensitivity is Increased in Tinnitus Ears
}

\author{
Sylvie Hébert, ${ }^{1,2}$ Philippe Fournier, ${ }^{1,2}$ and Arnaud Noreña ${ }^{3}$ \\ ${ }^{1}$ School of Speech Pathology and Audiology, Faculty of Medicine, and ${ }^{2}$ International Laboratory for Research on Brain, Music, and Sound, \\ Université de Montréal, Montreal, Quebec H3C 3J7, Canada, and 3'Université Aix-Marseille, Fédération de Recherche 3C, CNRS UMR 7260, F-13284 \\ Marseille, France
}

Increased auditory sensitivity, also called hyperacusis, is a pervasive complaint of people with tinnitus. The high prevalence of hyperacusis in tinnitus subjects suggests that both symptoms have a common origin. It has been suggested that they may result from a maladjusted increase of central gain attributable to sensory deafferentation. More specifically, tinnitus and hyperacusis could result from an increase of spontaneous and stimulus-induced activity, respectively. One prediction of this hypothesis is that auditory sensitivity should be increased in tinnitus compared with non-tinnitus subjects. The purpose of this study was to test this prediction by examining the loudness functions in tinnitus ears $(n=124)$ compared with non-tinnitus human ears $(n=106)$. Because tinnitus is often accompanied by hearing loss and that hearing loss makes it difficult to disentangle hypersensitivity (hyperacusis) to loudness recruitment, tinnitus and non-tinnitus ears were carefully matched for hearing loss. Our results show that auditory sensitivity is enhanced in tinnitus subjects compared with non-tinnitus subjects, including subjects with normal audiograms. We interpreted these findings as compatible with a maladaptive central gain in tinnitus.

\section{Introduction}

Loudness, the subjective perception of sound level, is one of the major perceptual attributes of sounds. Although the relationship between loudness and sound level is generally monotonic, the details of the loudness function can vary depending on hearing status or acoustic conditions. For instance, sensorineural hearing loss is accompanied by "loudness recruitment," namely steeper than normal loudness functions in the vicinity of the elevated thresholds (Moore et al., 1985; Stillman et al., 1993). In normal hearing, it has been suggested recently that loudness functions could be "plastic," because auditory sensitivity could be rescaled as a function of the mean level of auditory sensory inputs. In brief, a reduction of sensory inputs would be associated with an increase of auditory sensitivity, whereas an enhancement of inputs would be associated with a decrease of auditory sensitivity (Formby et al., 2003; Munro and Blount, 2009). Moreover, hyperacusis, defined as a hypersensitivity to moderate sounds, can be conceived as a "pathology" of loudness. Several studies have reported high hyperacusis scores for tinnitus individuals when using questionnaires (Hébert et al., 2004; Dauman and Bouscau-

\footnotetext{
Received July 19, 2012; revised Nov. 26, 2012; accepted Nov. 29, 2012.

Author contributions: S.H., P.F., and A.N. designed research; P.F. performed research; S.H., P.F., and A.N. analyzed data; S.H. and A.N. wrote the paper.

This work was supported by the Caroline-Durand Foundation, Fonds de recherche du Québec-Santé (FRQS), Institut de recherche Robert-Sauvé en santé et en sécurité du travail (IRSST), and Agence Nationale de la Recherche Grant ANR-2010-JCJC-1409-1. We thank two anonymous reviewers for their insightful comments on a previous version of this manuscript.

The authors declare no competing financial interests.

Correspondence should be addressed to Dr. Sylvie Hébert, International Laboratory for Research on Brain, Music, and Sound, Pavilion 1420 Mont-Royal, School of Speech Pathology and Audiology, Faculty of Medicine, Université de Montréal, P.0. Box 6128, Succursale Centre-Ville, Montreal, QC H3C 3J7, Canada. E-mail: sylvie.hebert@umontreal.ca.

DOI:10.1523/JNEUROSCI.3461-12.2013

Copyright $\odot 2013$ the authors $\quad 0270-6474 / 13 / 322356-09 \$ 15.00 / 0$
}

Faure, 2005; Hébert and Carrier, 2007; Fournier and Hébert, 2012). Discomfort loudness levels, i.e., the level at which a sound is judged as too loud, have also been found as predictive of both tinnitus prevalence and severity (Hébert et al., 2012) and more so than hearing loss, indicating an intimate relationship between tinnitus and sensitivity to sound. The high prevalence of hyperacusis in tinnitus individuals suggests a common origin of both symptoms. In this context, hyperacusis and tinnitus have been suggested to result from an increase of central gain: hearing loss, by reducing sensory inputs, would lead to an increase of central gain (Noreña and Chery-Croze, 2007; Noreña, 2011), even when hearing loss is not detectable on the audiogram (Schaette and McAlpine, 2011). An increase of central gain would amplify spontaneous and stimulus-induced activity, which then could lead to tinnitus and hyperacusis, respectively.

In the present study, we tested this hypothesis about a link between tinnitus and an enhanced central gain by assessing the loudness functions of individuals with tinnitus from a categorization task. We assumed that central gain could be estimated through the characteristics of the loudness functions. More specifically, we hypothesized in ears of tinnitus individuals that lower sound levels (in decibels) would be attributed to moderateto-loud sound categories compared with ears of controls without tinnitus but with similar hearing loss.

In addition, hyperacusis should be behaviorally distinguishable from loudness recruitment. In loudness recruitment, loudness "catches up," and sounds are judged as loud as sounds presented in a normal ear regardless of the extent of the elevation of the hearing thresholds (HTs) (Moore et al., 1985; Stillman et al., 1993). Therefore, in ears with various degrees of hearing loss without tinnitus, loudness recruitment should be observable by merged loudness curves at high sound levels, whereas loudness functions should remain parallel in tinnitus ears. 

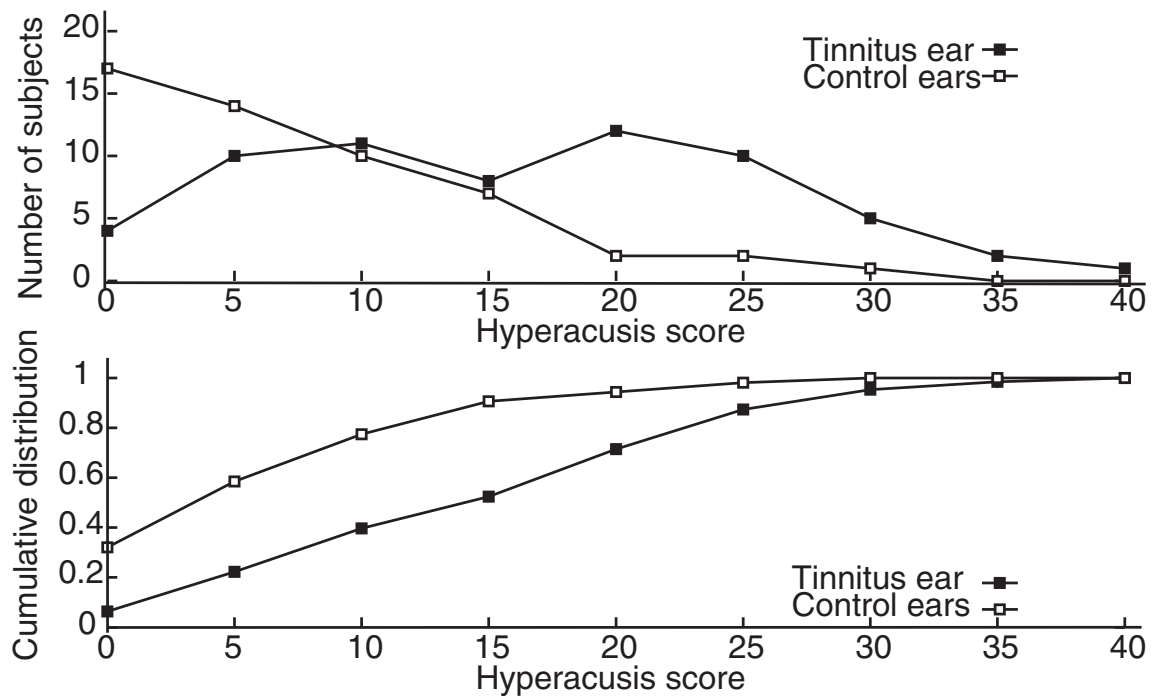

Figure 1. Distribution (top) and cumulative distribution (bottom) of auditory sensitivity scores obtained from the Khalfa questionnaire. Nearly $80 \%$ of control participants (white squares) present a score below 10 , whereas the percentage is $40 \%$ in the tinnitus group (black squares), indicating that auditory sensitivity is enhanced in tinnitus participants.

Table 1. Mean absolute thresholds in $\mathrm{AB}$ HL for 1 and $4 \mathrm{kHz} /$ edge frequency for the tinnitus and control ears in each hearing-loss category

\begin{tabular}{lrll}
\hline & \multicolumn{3}{l}{ Mean thresholds for $1 \mathrm{kHz}$} \\
\cline { 2 - 4 } Classification & $\begin{array}{l}\text { Tinnitus } \\
\text { ears }(n)\end{array}$ & $\begin{array}{l}\text { Control } \\
\text { ears }(n)\end{array}$ & $\begin{array}{l}p \\
\text { value }\end{array}$ \\
\hline 1 kHz & & & \\
0, Normal hearing (-10 to 15 dB HL) & $8(75)$ & $7(73)$ & 0.30 \\
1, Slight hearing loss (16-25 dB HL) & $20(23)$ & $19(14)$ & 0.35 \\
2, Mild hearing loss (26-40 dB HL) & $34(12)$ & $34(7)$ & 0.85 \\
3, Moderate-to-profound hearing loss (>56 dB HL) & $54(14)$ & $50(12)$ & 0.09 \\
Total number of ears & 124 & 106 & \\
4 kHz & & & \\
0, Normal hearing (-10 to 15 dB HL) & $3(44)$ & $2(46)$ & 0.84 \\
1, Slight hearing loss (16-25 dB HL) & $20(22)$ & $20(24)$ & 0.79 \\
2, Mild hearing loss (26-40 dB HL) & $31(22)$ & $31(17)$ & 0.94 \\
3, Moderate-to-profound hearing loss (>56 dB HL) & $63(38)$ & $66(19)$ & 0.51 \\
Total number of ears & 126 & 106 & \\
\hline
\end{tabular}

\section{Materials and Methods}

Participants

Tinnitus participants were 63 adults (24 women), with a mean \pm SD age of $54 \pm 16$ years, and a mean \pm SD education level of $15 \pm 3$ years. Control participants without tinnitus were 53 adults ( 29 women), with a mean \pm SD age of $52 \pm 17$ years and a mean \pm SD education level of $16 \pm$ 4 years. The two groups did not differ in age or education level (both $t<$ 1 by independent $t$ tests). Tinnitus and control participants differed with respect to their hyperacusis scores as assessed psychometrically (Khalfa et al., 2002), with mean \pm SD scores of $18.5 \pm 10.0$ and $9.2 \pm 7.4$ for the two groups, respectively $\left(t_{(114)}=-5.62, p<0.001\right)$.

To assess the profile of hearing loss in the tinnitus and control groups, each participant's ear was classified into one of four hearing-loss category according to its own detection threshold [in decibels hearing level (dB HL) converted from decibels sound pressure level (dB SPL) $]$ at 1 and $4 \mathrm{kHz} /$ edge frequency separately (see procedure below): 0 , normal hearing ( -10 to 15 $\mathrm{dB} \mathrm{HL}) ; 1$, slight hearing loss (16-25 dB HL); 2, mild hearing loss (26-40 dB $\mathrm{HL}) ; 3$, moderate hearing loss (41-55 dB HL); and 4, moderately severe, severe, or profound hearing loss (>56 dB HL) (Clark, 1981).

Therefore, one given ear could be classified into one category for $1 \mathrm{kHz}$ and into another category for $4 \mathrm{kHz}$. Clark's original categories 3 and 4 were merged because of the small number of control ears in the moderately severe, severe, or profound hearing loss at $1 \mathrm{kHz}(n=1)$. Final categories therefore went from 0 (normal hearing) to 3 (moderate-to- profound hearing loss). Ears of tinnitus participants were considered as tinnitus ears even when tinnitus was unilateral $(n=37)$ based on the rationale that increased sensitivity is bilateral even when tinnitus is unilateral (as reported by Formby and Gold, 2002). In addition, in our experience, participants reporting unilateral tinnitus often have bilateral tinnitus, but one side is louder than the other side and therefore tinnitus is perceived as coming only from the louder side. This is particularly striking when participants experience residual inhibition of their tinnitus on the louder side and they "discover" another tinnitus in their other ear. Because in this study we did not measure tinnitus per se, we could not be $100 \%$ sure that all of the participants could accurately localize their tinnitus. In this context, both ears in subjects with unilateral tinnitus have been grouped. The total number of ears was 126 from tinnitus participants and 106 from control participants without tinnitus, for a total of 232 ears.

\section{Tasks and apparatus}

Hearing thresholds were measured in dB SPL in half-octave frequency steps from 250 to $8000 \mathrm{~Hz}$ using an adaptive procedure $(-5,+3,-1,+1)$. More specifically, an initial sound level between 50 and $60 \mathrm{~dB}$ SPL (randomly selected) was presented. This level was decreased by $5 \mathrm{~dB}$ steps until the sound was not heard anymore, then increased by $3 \mathrm{~dB}$ steps until it was heard again, then decreased and increased by $1 \mathrm{~dB}$ steps for eight more reversals. A total of nine reversals were obtained, and the threshold was determined as the mean of the last eight reversals. The procedure was repeated for each frequency using a randomized order of presentation. The task was to signal whether or not a sound was heard. A two-button response box was used.

Edge frequency thresholds were assessed for all participants with hearing loss (tinnitus and control). After the HTs were obtained for all frequencies, the program automatically scanned every two octave-related frequencies and selected the frequency at the bottom edge of a slope of at least $20 \mathrm{~dB}$ /octave. This frequency then became the central frequency around which thresholds were assessed in $1 / 8$ octave steps with the same bracketing procedure as above. The edge frequency was the frequency at the beginning of the slope and which differed from the next adjacent frequency from at least $5 \mathrm{~dB}$.

Discomfort thresholds (DTs) were measured in dB SPL for frequencies 1,2 , and $4 \mathrm{kHz}$ or edge frequency by starting at a low sound level randomly selected between 50 and $60 \mathrm{~dB}$ SPL and increasing the level by $5 \mathrm{~dB}$ steps. The task was to signal when the sound became uncomfortably loud. A two-button response box was used. A maximum sound level of $115 \mathrm{~dB}$ SPL was presented, and this level was considered as the final response if participants had not yet pressed the button.

Loudness growth in half-octave bands (Noreña and Chery-Croze, 2007), adapted from Allen et al. (1990), was measured in dB SPL for frequencies 1 and $4 \mathrm{kHz}$ (or edge frequency) at SPLs spanning the entire dynamic range of each ear, i.e., between the previously determined HTs and DTs, split into 15 equal level steps. Stimuli were presented six times at each level in a pseudorandom order with the constraint of having no more than the same sound levels twice in a row. The task was to categorize loudness into one of seven categories: (1) inaudible; (2) very soft; (3) soft; (4) OK; (5) loud; (6) very loud; or (7) too loud. Category levels were determined by averaging the attributions. For example, if the OK category was attributed to levels 58 (first presentation), 39 (second presentation), and 58 (third presentation), the resulting "OK" level was $(58+39+58) / 3=52 \mathrm{~dB}$ SPL. Participants were not instructed to use every possible category, and therefore some categories were not used. A seven-button response box was used.

For all three tasks, stimuli were trains of pure tones of $300 \mathrm{~ms}$ each separated by $300 \mathrm{~ms}$ of silence ( $20 \mathrm{~ms}$ rise and fall). The tasks were 
programmed with MATLAB (R2006a) and completely automated using a Tucker Davis Technology-3 system (a real-time signal processing system).

\section{Procedure}

Testing took place in a sound-attenuating booth using Sennheiser HD265 headphones calibrated with a Larson Davis sound level meter coupled with an artificial ear AEC101 and a 2559 model microphone. All participants were tested on the HTs (edge frequency if applicable), DTs, and loudness growth tasks in this order. Right and left ears were tested in a counterbalanced order across participants. The whole testing session took $\sim 2 \mathrm{~h}$.

\section{Data analyses}

Classification into hearing-loss categories. Independent samples $t$ tests were used to verify that there were no differences between HTs of tinnitus and control ears for each frequency ( 1 vs $4 \mathrm{kHz} /$ edge) separately. Independent samples $t$ tests (or Mann-Whitney $U$ tests when $n$ values were small) were also used to examine whether ears in each hearing-loss category differed in their respective discomfort levels.

HTs and DTs. HTs at each frequency and DTs at 1,2, and $4 \mathrm{kHz} /$ edge were averaged for right and left ears separately for the tinnitus and control groups. The dynamic range was calculated by subtracting the absolute threshold value from the DT value.

Loudness functions between ear groups. The slopes of the loudness functions for each ear group (tinnitus vs control) at both 1 and $4 \mathrm{kHz} /$ edge frequency were first calculated by comparing linear and power regressions on all points for each hearing-loss category. The linear regression provided the best fit (similar to Al-Salim et al., 2010). Between-group comparisons were calculated using $t$ tests. When slope differences were significant, independent samples $t$ tests were run between ear groups (tinnitus vs control) at each loudness category (from inaudible to too loud) to specify differences between loudness categories.

Loudness functions within ear groups. In addition to the differences between ear groups, univariate ANOVAs were run for each ear group (tinnitus and control) and each frequency ( 1 and 4 $\mathrm{kHz} /$ edge), with hearing-loss category ( 0 to 3 ) as the between-subject factor to assess whether functions would merge or stay parallel at high sound levels, i.e., to assess the presence of recruitment. Tukey's post hoc comparisons were run to assess group differences.

No correction for multiple comparisons was applied because groups of ears (number of data points) could differ from one loudness category to another. Statistics were run with IBM SPSS 19.0.

\section{Results}

\section{Hyperacusis questionnaire}

Figure 1 shows the distribution (top) and the cumulative distribution (bottom) of auditory sensitivity score obtained from the Khalfa questionnaire. Nearly $80 \%$ of control subjects present a score below 10 , whereas the percentage is $40 \%$ in the tinnitus group, indicating that auditory sensitivity is enhanced in tinnitus subjects.

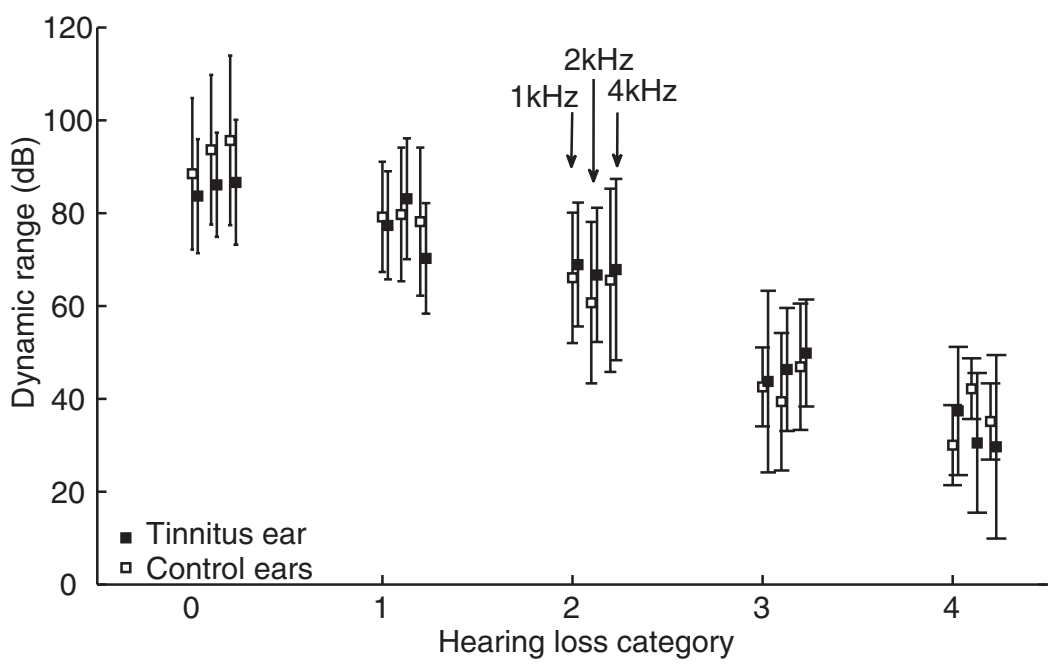

Figure 2. The dynamic range (discomfort level - absolute threshold) for the three frequencies tested (1, 2, and $4 \mathrm{kHz})$ as a all three frequencies only in the group in which the absolute thresholds were within normal range. Hearing-loss category: 0 , normal hearing; 1, slight hearing loss; 2, mild hearing loss; 3, moderate-to-profound hearing loss.

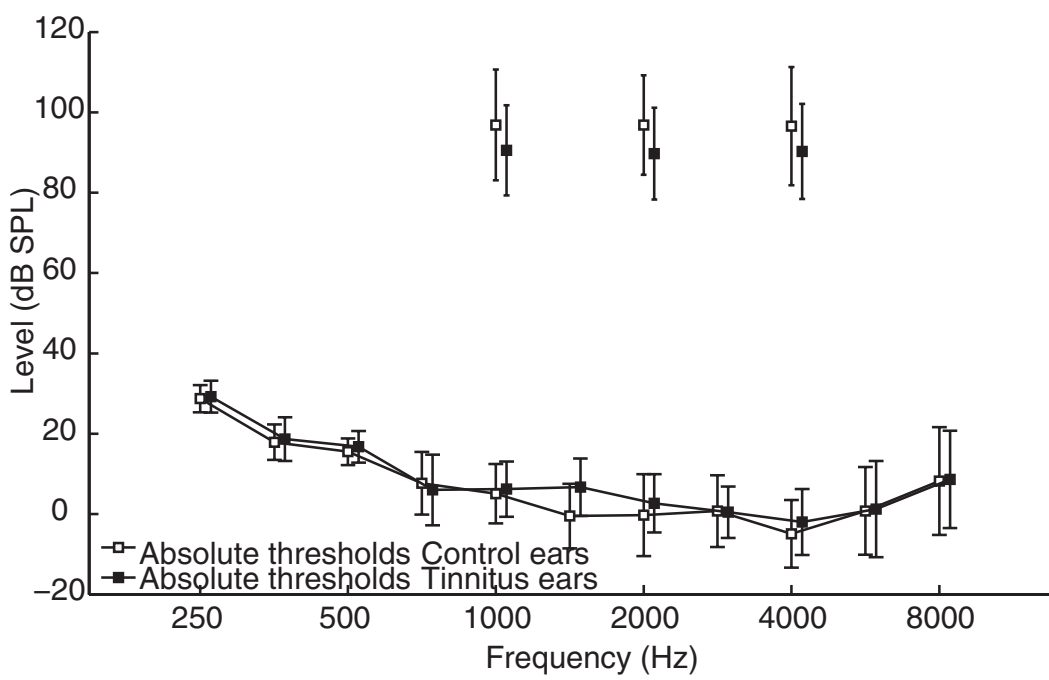

Figure 3. Mean absolute thresholds and discomfort levels for tinnitus (black squares) and control (white squares) ears. Absolute thresholds are within normal range at all frequencies, but the dynamic range was lower at all tested frequencies in the tinnitus ears.

\section{Edge frequencies}

The percentage of ears with an identifiable edge frequency was $33 \%$ in both groups. Edge frequencies for tinnitus $(n=42)$ and control $(n=35)$ ears did not differ from each other, with means of 2975 and $2857 \mathrm{~Hz}$, respectively $(t<1)$. When considering only edge frequencies with normal HTs $(<15 \mathrm{~dB} \mathrm{HL})$, the percentage of identifiable edge frequencies dropped to $<15 \%$ of all ears in each group (tinnitus ears, $n=15$; controls ears, $n=14$ ). When merging ears with edge frequency with ears for which thresholds were obtained at $4 \mathrm{kHz}$, average frequencies were 3658 and $3623 \mathrm{~Hz}$ for tinnitus and control ears, respectively $(t<1)$. Data for edge frequencies and $4 \mathrm{kHz}$ were collapsed given that the proportions of edge frequencies in both groups were the same $(33 \%)$ and that the mean frequency was close to $4 \mathrm{kHz}$ in each group.

\section{Classification in hearing-loss categories}

Table 1 displays the number of ears and mean HTs (in dB HL) of the tinnitus and controls ears, separately for 1 and $4 \mathrm{kHz} / \mathrm{edge}$ 
Table 2. Slope values for tinnitus and control ears for all hearing-loss groups

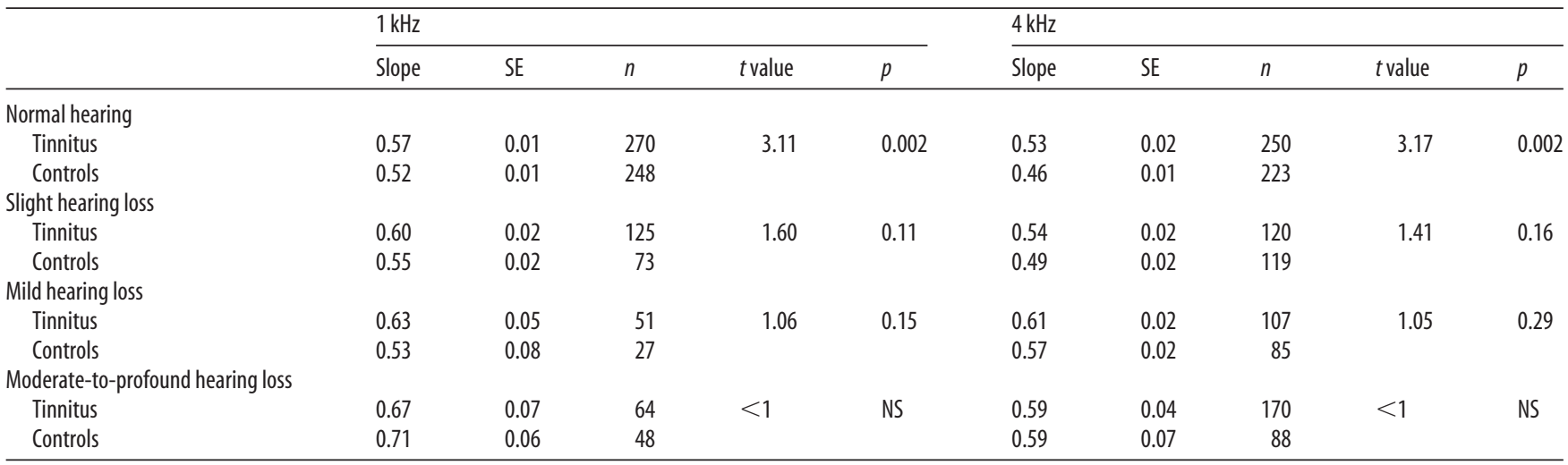

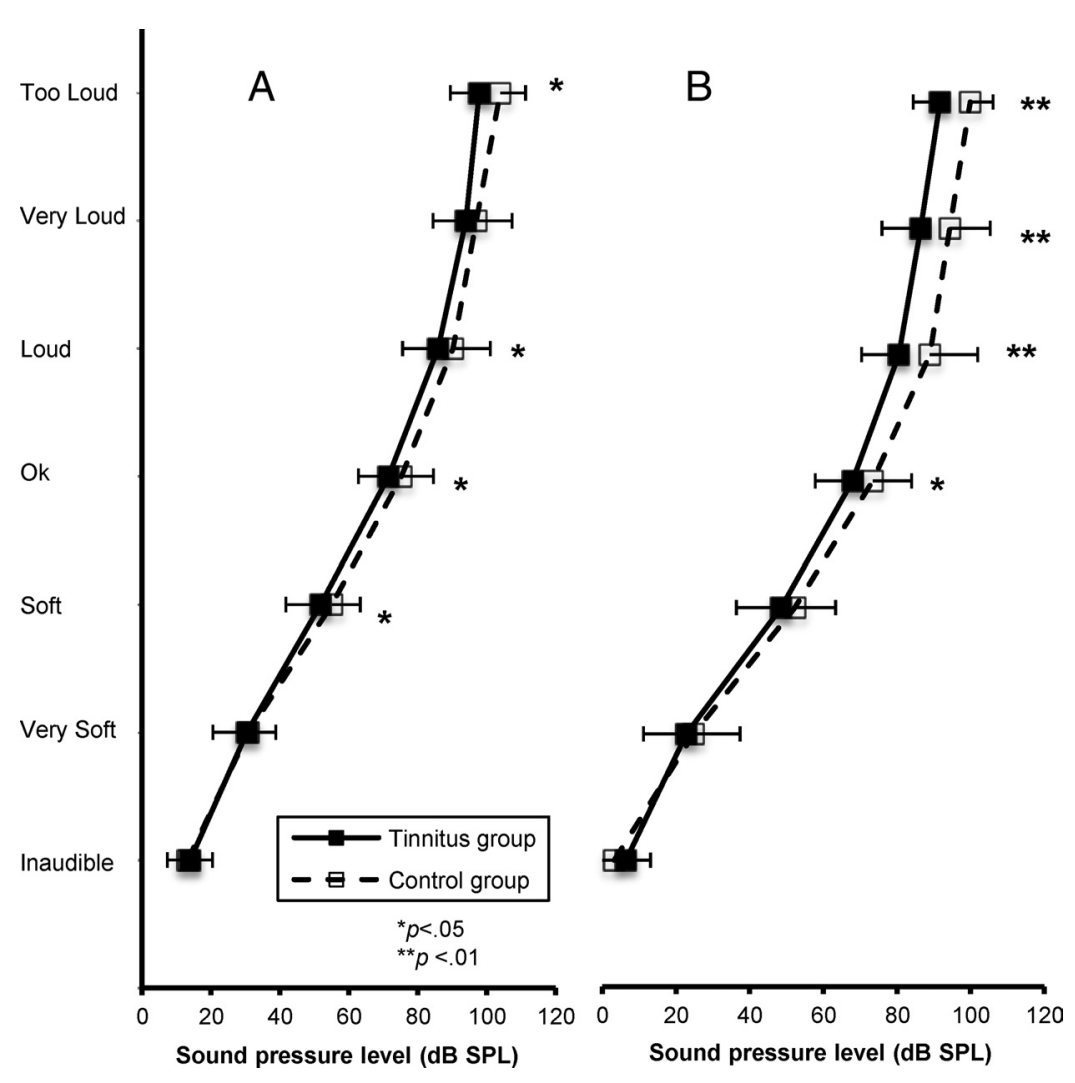

Figure 4. Averaged loudness functions obtained from tinnitus (black squares) and control (white squares) normal-hearing ears at 1 (A) and $4 \mathrm{kHz} /$ edge (B).

frequency, after classification in each hearing-loss category. For 1 $\mathrm{kHz}$, tinnitus ears had higher thresholds than control ears in category 3 (moderate-to-profound hearing loss), with means of 56.4 and $49.5 \mathrm{~dB}$ HL, respectively $\left(t_{(26)}=-2.27, p=0.03\right)$. Data points exceeding 2 SDs from the mean of the two ear groups for 1 $\mathrm{kHz}$ were therefore excluded ( $n=2$ tinnitus ears). After correction, the resulting threshold difference was not significant, with means of 54.1 and $49.5 \mathrm{~dB} \mathrm{HL}$, respectively $\left(t_{(24)}=-1.77, p=\right.$ 0.09 ). The outliers were not included in subsequent analyses. There were no other significant differences between thresholds at any of the hearing-loss categories for any of the two frequencies.

\section{HTs and discomfort levels}

Figure 2 shows the dynamic range for the three frequencies tested $(1,2$, and $4 \mathrm{kHz})$ as a function of the hearing-loss category. Con- trol and tinnitus groups are significantly different at all three frequencies only in the group in which the absolute thresholds were within normal range (MannWhitney $U$ test, $p<0.05$, no correction for multiple comparisons).

A reduced dynamic range (increased sensitivity to sound) at a frequency when no hearing loss is present could reflect hearing loss at a different frequency. To address this specific question, tinnitus and control ears showing absolute thresholds within normal range at all frequencies (i.e., not exceeding $20 \mathrm{~dB}$ HL for frequencies $250 \mathrm{~Hz}$ to $8 \mathrm{kHz}$ ) were compared. Each group was composed of 19 ears (12 of 19 ears were from six participants in the tinnitus group). Figure 3 shows the absolute thresholds and the discomfort levels for the two groups. On average, the dynamic range was lower at all tested frequencies in the tinnitus subjects, with means of 84 versus 91, 87 versus 97, and 92 versus 101 for 1,2 , and $4 \mathrm{kHz}$, respectively, but the decrease was significantly lower in the tinnitus ears at $2 \mathrm{kHz}$ only with $p$ values of $0.10,0.03$, and 0.08 , respectively (by independent $t$ tests, no correction for multiple comparisons).

This result suggests that an increase in auditory sensitivity is present in tinnitus subjects, even when they have normal thresholds over a broad frequency band. Assuming that an increase in auditory sensitivity results from cochlear lesions (causing a decrease in afferent inputs and an increase of central gain), this result suggests that the audiogram cannot detect these particular cochlear lesions. The study by Kujawa and Liberman (2009) and Schaette and McAlpine (2011) have shown why this would be the case (see Discussion).

The question of whether or not there is an increase in sensitivity in ears with an edge frequency for which the edge frequency threshold is within normal limits was also addressed. Discomfort levels of edge frequencies for which HTs were within normal limits $(<15 \mathrm{~dB}$ HL) were compared between tinnitus $(n=13)$ and controls $(n=10)$ ears. Control and tinnitus ears were significantly different (Mann-Whitney $U=30.5, p=0.03$, two-tailed test), with a mean of 98.5 and $86.5 \mathrm{~dB} \mathrm{SPL}$, respectively. The mean 
value of the edge frequency (tinnitus, $2993 \mathrm{~Hz}$; controls, $3533 \mathrm{~Hz}$ ) did not differ between groups $\left(t_{(21)}=1.0, p=0.3\right)$.

Tinnitus ears with normal hearing display hyperacusis Tinnitus and control ears with similar hearing levels were compared to assess whether hyperacusis could be shown in tinnitus ears.

Normal-hearing ear groups

Averaged loudness functions with fitted regression lines obtained from tinnitus and control ears at 1 and $4 \mathrm{kHz} /$ edge for all hearingloss categories are presented in Table 2.

At $1 \mathrm{kHz}$ for normal hearing, loudness functions of tinnitus ears were significantly steeper than for control ears, with slopes of 0.57 and 0.52 , respectively $(p=0.002)$ (Table 2$). t$ tests run between categories revealed that differences were significant from the soft level up to the too loud level, except for the very loud level (Fig. 4A; Table 3).

At $4 \mathrm{kHz}$ or edge frequency for normal hearing, loudness functions of tinnitus ears were also significantly steeper than for control ears, with slopes of 0.53 and 0.46 , respectively $(p=0.002)$ (Fig. 5A; Table 2). $t$ tests run between categories revealed that differences were significant from the OK level up to the too loud level (Fig. 4B; Table 3).

Other hearing-loss ear groups

For all of the other hearing-loss ear groups, slopes were overall steeper for tinnitus compared with control ears (Fig. $5 B$ ), but the differences were not significant (Table 2). To note, sample sizes were small at high sound levels.

\section{Hyperacusis versus loudness \\ recruitment: within-ear \\ group differences}

Figure 6 shows averaged loudness functions obtained from tinnitus and control ears for each hearing-loss category (from 0 to 3 ) and each frequency. One can see at a glance that, for both frequencies, but more strikingly at $4 \mathrm{kHz} /$ edge, loudness curves in tinnitus ears remain essentially parallel at high sound levels, whereas control ears display typical loudness recruitment curves. This was supported by statistical analysis.

\section{Tinnitus ears}

At $1 \mathrm{kHz}$, level differences between hearingloss groups were significant for loudness categories from inaudible to loud: inaudible, $F_{(3,100)}=199.1, p<0.001$; very soft, $F_{(3,119)}=59.11, p<0.001$; soft, $F_{(3,120)}=$ 21.69, $p<0.001$; OK, $F_{(3,117)}=12.48, p<$ 0.001 ; loud, $F_{(3,111)}=3.63, p=0.015$; very loud, $F_{(3,70)}=1.18, p=0.33$; too loud, $F<1$.

At $4 \mathrm{kHz} /$ edge, level differences between hearing-loss groups were significant for all loudness categories: inaudible, $F_{(3,82)}=116.28, p<$ 0.001 ; very soft, $F_{(3,120)}=95.37, p<0.001$; soft, $F_{(3,121)}=40.02$, $p<0.001$; OK, $F_{(3,117)}=23.51, p<0.001$; loud, $F_{(3,104)}=12.04$, $p<0.001$; very loud, $F_{(3,64)}=3.23, p=0.028$; too loud, $F_{(2,20)}=$ $5.15, p=0.016$.
Table 3. Comparisons between loudness categories of normal-hearing tinnitus and control ears at 1 and $4 \mathrm{kHz}$

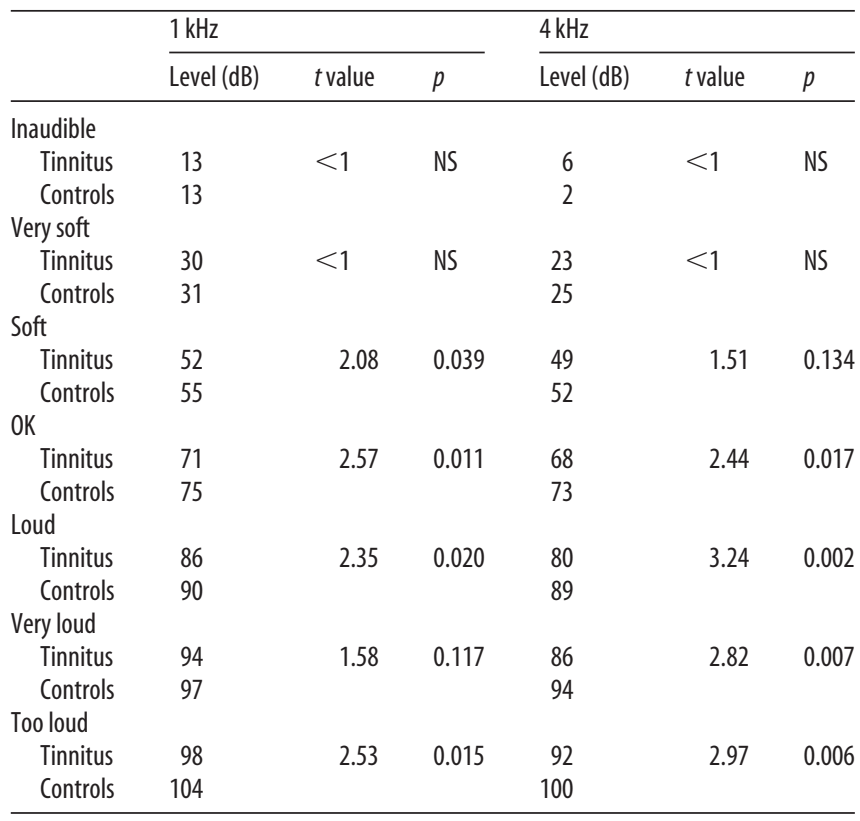

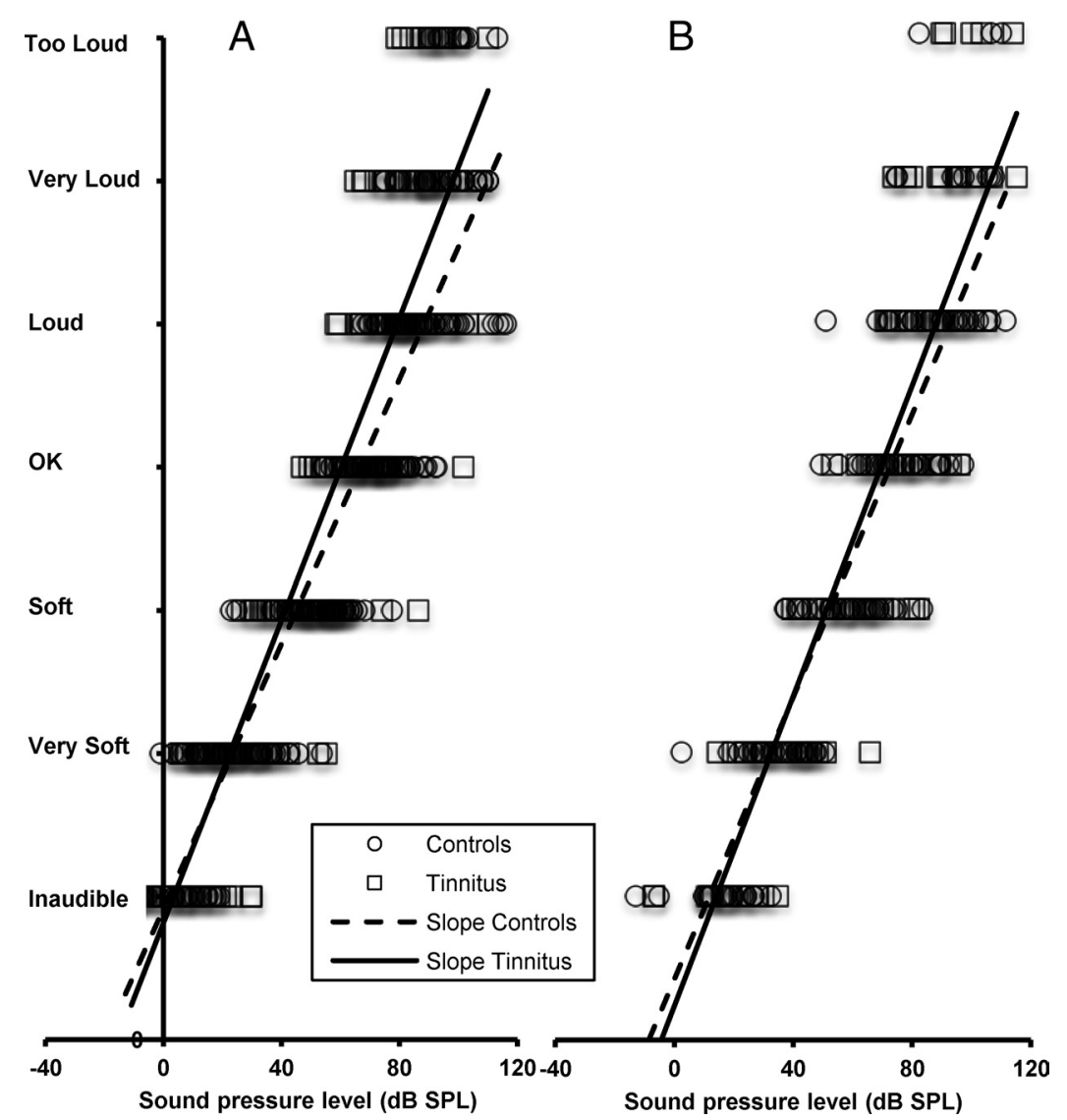

Figure 5. $\quad \boldsymbol{A}, \boldsymbol{B}$, Slopes of loudness functions obtained at $4 \mathrm{kHz} /$ edge from tinnitus (plain lines) and control (dotted lines) ears for normal hearing $(\boldsymbol{A})$ and slight hearing loss $(\boldsymbol{B})$. 


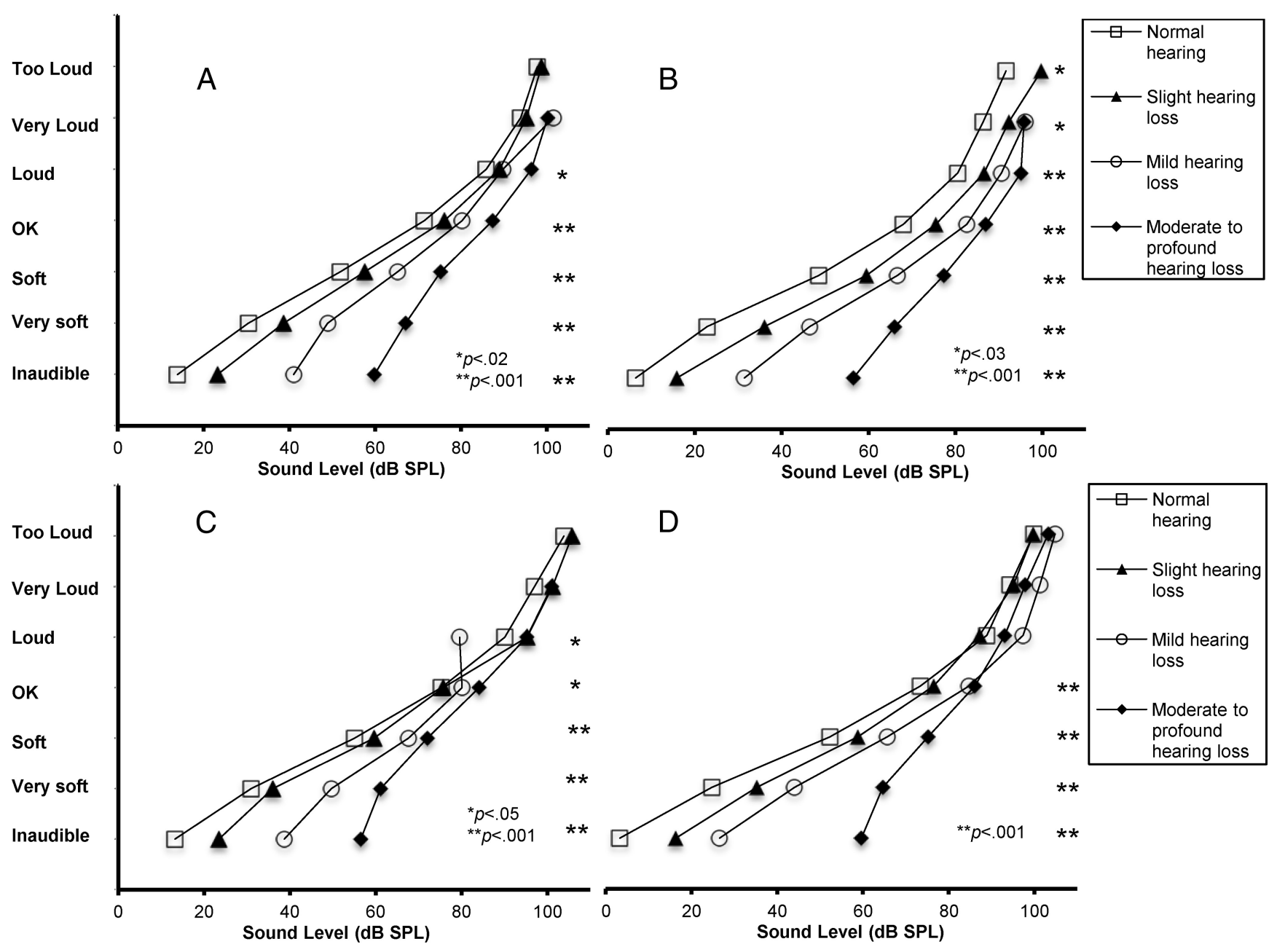

Figure 6. $\quad \boldsymbol{A}-\boldsymbol{D}$, Averaged loudness functions obtained from tinnitus ears for $1 \mathrm{kHz}(\boldsymbol{A})$ and $4 \mathrm{kHz}(\boldsymbol{B})$ and control ears for $1 \mathrm{kHz}(\boldsymbol{C})$ and $4 \mathrm{kHz}(\boldsymbol{D})$, with respect to hearing-loss category (from 0 to 3). Loudness curves in tinnitus ears remain essentially parallel at high sound levels, whereas control ears display typical loudness recruitment curves.

$2.73, p=0.048$; loud, $F_{(3,87)}=2.88, p=0.041$; very loud, $F<1$; too loud, $F_{(2,20)}=2.56, p=0.102$.

At $4 \mathrm{kHz} /$ edge, level differences between hearing-loss groups were significant for the lower loudness categories inaudible, very soft, soft, and $\mathrm{OK}$ and tapered off at the loud, very loud, and too loud levels: inaudible, $F_{(3,65)}=65.20, p<0.001$; very soft, $F_{(3,97)}=$ 43.73, $p<0.001$; soft, $F_{(3,97)}=19.93, p<0.001 ; \mathrm{OK}, F_{(3,93)}=8.25$, $p<0.001$; loud, $F_{(3,83)}=2.41, p=0.073$; very loud, $F_{(3,45)}=1.06$, $p=0.375$; too loud, $F<1$.

Tukey's post hoc comparisons showing ear group differences within tinnitus and control ears (normal hearing to moderate hearing loss) are presented in Table 4. Overall, at both 1 and 4 $\mathrm{kHz}$ /edge, tinnitus ear groups differ more among themselves than control ears, meaning that control ears display classical loudness recruitment but, in tinnitus ears, loudness does not (or less so) catch up.

\section{Discussion}

This paper reports two important novel findings. The first finding was that sensitivity to loud sounds (hyperacusis, measured by loudness growth functions) was increased in individuals with tinnitus compared with normal hearing individuals, even when thresholds were in the range of normal hearing and did not differ between the groups. Moreover, this increased sensitivity could be observed for two different frequencies, although it was more evident at high ( $4 \mathrm{kHz} /$ edge) than at lower $(1 \mathrm{kHz})$ frequency. Although some groups have reported loudness functions in tinnitus (Penner, 1986; Ward and Baumann, 2009; Reavis et al., 2012), our findings are the first to report loudness functions in a significant number of tinnitus and control ears matched for hearing loss. The dynamic range of acceptable sound intensities was also reduced in individuals with tinnitus compared with controls (all subjects with normal HTs) because of reduced sound level tolerance in the subjects with tinnitus. We suggest that loudness growth functions found in tinnitus are the perceptual correlate of the hyperacusis complaint by individuals with tinnitus (as confirmed herein by questionnaire data) and that hyperacusis results from a maladaptive central gain.

The second important and novel finding is that, when considering several degrees of hearing loss from slight to profound, loudness growth curves in tinnitus ears show more sensitivity than non-tinnitus control ears, that is, loudness growth curves remain basically parallel at high sound levels (i.e., more different from one hearing-loss category to another). In contrast, non-tinnitus control ears with hearing loss displayed typical full loudness recruitment, with loudness growth curves merging at high sound levels. Our findings also 
Table 4. Post hoc comparisons ( $p$ values) between hearing-loss groups for tinnitus and control ears separately at 1 and $4 \mathrm{kHz} /$ edge for each loudness category

\begin{tabular}{|c|c|c|c|c|c|c|}
\hline & \multicolumn{2}{|c|}{ Slight hearing loss (B) } & \multicolumn{2}{|c|}{ Mild hearing loss (C) } & \multicolumn{2}{|c|}{$\begin{array}{l}\text { Moderate hearing loss } \\
\text { (D) }\end{array}$} \\
\hline & Tinnitus & Control & Tinnitus & Control & Tinnitus & Control \\
\hline \multicolumn{7}{|c|}{$1 \mathrm{kHz}$} \\
\hline \multicolumn{7}{|c|}{ Inaudible } \\
\hline A & 0.001 & 0.003 & 0.001 & 0.001 & 0.001 & 0.001 \\
\hline B & & & 0.001 & 0.002 & 0.001 & 0.001 \\
\hline c & & & & & 0.001 & 0.002 \\
\hline \multicolumn{7}{|c|}{ Very soft } \\
\hline A & 0.003 & NS & 0.001 & 0.001 & 0.001 & 0.001 \\
\hline B & & & 0.025 & 0.001 & 0.001 & 0.001 \\
\hline C & & & & & 0.001 & 0.015 \\
\hline \multicolumn{7}{|l|}{ Soft } \\
\hline A & NS & NS & 0.001 & 0.008 & 0.001 & 0.001 \\
\hline B & & & NS & NS & 0.001 & 0.009 \\
\hline c & & & & & NS & NS \\
\hline \multicolumn{7}{|l|}{ OK } \\
\hline A & NS & NS & 0.026 & NS & 0.001 & 0.04 \\
\hline B & & & NS & NS & 0.004 & NS \\
\hline C & & & & & NS & NS \\
\hline \multicolumn{7}{|l|}{ Loud } \\
\hline A & NS & NS & NS & NS & 0.011 & NS \\
\hline B & & & NS & NS & NS & NS \\
\hline$C$ & & & & & NS & NS \\
\hline \multicolumn{7}{|c|}{$\begin{array}{l}4 \mathrm{kHz} \\
\text { Inaudib }\end{array}$} \\
\hline A & 0.023 & 0.003 & $<0.001$ & $<0.001$ & $<0.001$ & $<0.001$ \\
\hline B & & & $<0.001$ & NS & $<0.001$ & $<0.001$ \\
\hline C & & & & & $<0.001$ & $<0.001$ \\
\hline \multicolumn{7}{|c|}{ Very soft } \\
\hline A & $<0.001$ & 0.009 & $<0.001$ & $<0.001$ & $<0.001$ & $<0.001$ \\
\hline B & & & 0.018 & NS & $<0.001$ & $<0.001$ \\
\hline$C$ & & & & & $<0.001$ & $<0.001$ \\
\hline \multicolumn{7}{|l|}{ Soft } \\
\hline A & 0.004 & NS & $<0.001$ & $<0.001$ & $<0.001$ & $<0.001$ \\
\hline B & & & NS & NS & $<0.001$ & $<0.001$ \\
\hline C & & & & & 0.007 & NS \\
\hline \multicolumn{7}{|l|}{$\mathrm{OK}$} \\
\hline A & 0.039 & NS & $<0.001$ & 0.002 & $<0.001$ & $<0.001$ \\
\hline B & & & NS & NS & 0.001 & 0.031 \\
\hline$C$ & & & & & NS & NS \\
\hline \multicolumn{7}{|l|}{ Loud } \\
\hline A & NS & NS & 0.005 & NS & $<0.001$ & NS \\
\hline B & & & NS & NS & 0.023 & NS \\
\hline C & & & & & NS & NS \\
\hline
\end{tabular}

The $p$ values in bold represent cases in which control ear groups did not differ from one another (showing loudness recruitment), whereas tinnitus ear groups differed from one another (showing differences in sensitivity). Very loud and too loud categories had too few data points and are not presented. A, Normal hearing; B, slight Hearing loss; $C$, mild hearing loss; $D$, moderate hearing loss.

suggest that hyperacusis and loudness recruitment can be experimentally distinguished from one another and that the complaint of increased sensitivity in tinnitus is different from loudness recruitment (Noreña, 2011; Zeng, 2012).

There is a large consensus around the idea that peripheral damage is necessary for tinnitus to occur (Eggermont and Roberts, 2004; Weisz et al., 2006; Gu et al., 2010). Recently, an abnormally increased central gain controlling neural sensitivity to compensate for deprived auditory input has been proposed to account for tinnitus (Chrostowski et al., 2011; Noreña, 2011; Schaette and McAlpine, 2011; Zhou et al., 2011). In this model, both spontaneous neural noise and sound-evoked activity are amplified and lead to a phantom sound (tinnitus) and pathology of loudness (hyperacusis), respectively. Therefore, because tinnitus and hyperacusis stem from the same mechanism, they are expected to be always associated to some extent. Our findings are partially compatible with this view. First, the increased sensitivity shown here in normal-hearing tinnitus ears could indicate some degree of central gain compensation for early damage to the auditory nerve not yet visible on the audiogram. The audiogram is a very coarse estimate of cochlear and neural functioning. Indeed, recent animal studies have shown that, even when HTs (assessed by auditory brain responses) are restored to normal after temporary threshold shift induced by sound exposure, $>50 \%$ of the cochlear nerve fibers were found to be degenerated, indicating that hidden and progressive neural damage could be invisible in the audiogram (Kujawa and Liberman, 2009; Lin et al., 2011). Other studies have reported findings consistent with hidden hearing loss in tinnitus subjects with normal audiogram (Weisz et al., 2006; Schaette and McAlpine, 2011). In particular, it has been reported that, although the amplitude of wave I (reflecting activity in the auditory nerve) is reduced in tinnitus ears with normal audiograms at sound levels $\geq 90 \mathrm{~dB}$ SPL, the amplitude of wave $\mathrm{V}$ is unchanged or even increased (Schaette and McAlpine, 2011; Gu et al., 2012). These results are consistent with functional damages affecting high-threshold auditory nerve fibers, followed by a compensatory amplification in higher auditory centers (i.e., the brainstem). Because in both studies broadband clicks were used, it is unknown which frequency region was involved, i.e., whether the decreased wave I and the increased wave V were only in the high-frequency range or in all of the frequency ranges. Damages can be local, but the central effects may affect a broad frequency band. In any case, our findings could thus represent such an instance of increased gain in the presence of hidden hearing loss. Moreover, because the difference between loudness functions was more prominent for high-level sounds (categories loud to too loud; Fig. 4), our data are in agreement with specific damage to the high-threshold auditory nerve fibers. Our data also suggest that the increase in gain is multiplicative, which is in agreement with the known effects of homeostatic plasticity (for review, see Noreña and Farley, 2012).

Our findings are also compatible with previous ones showing that hyperactivity, as reflected by DTs and loudness functions, is not restricted to the hearing-loss region, at least the one measurable with an audiogram (Noreña and CheryCroze, 2007). This was further shown here by the analysis of a subgroup of tinnitus ears with normal HTs at all tested frequencies $(250-8000 \mathrm{~Hz})$ displaying lower DTs compared with similar control ears. Current models of tinnitus that involve decreases in intracortical inhibition (Eggermont and Roberts, 2004) or increased central gain (Noreña, 2011) have proposed that the tinnitus percept is primarily linked to hyperactivity within the hearing-loss region. For instance, in the release of lateral inhibition model, more damage would predict less lateral inhibition within the hearing-loss region and, hence, higher hyperactivity (and its putative behavioral correlate, hypersensitivity to sounds). In the central gain model, more damage in the hearing-loss region would predict more central compensation and, hence, stronger hyperactivity. Both models suggest that hyperactivity would give rise to the tinnitus percept at a frequency inside the hearing-loss region. Studies that have attempted to identify the predominant tinnitus frequency have indeed reported that the predominant tinnitus pitch is within a hearing-loss region measurable with the audiogram (Norena et al., 2002; Roberts et al., 2008; Fournier and Hébert, 2012). Although the current study did not report tinnitus pitch, showing hypersensitivity to sounds over a 
broad range of frequencies suggests that stimulus-induced hyperactivity is not restricted to the measurable hearing-loss/ tinnitus frequency region. Our results therefore suggest a differentiation between hyperacusis and tinnitus: tinnitus could be related to increased neural synchrony within the hearing-loss region, whereas hyperacusis could be related to increased stimulus-induced activity over a broader frequency band, extending the hearing-loss region, as suggested previously (Eggermont and Roberts, 2004).

\section{Increased sensitivity, loudness recruitment, and central gain}

Recent studies investigating the neural response of the auditory nerve after acoustic trauma have shown decreases in the slope of input-output function of the auditory nerve (Heinz et al., 2005) and have proposed a central origin of recruitment (Joris, 2009). More specifically, loudness recruitment could be attributable to an adaptation of the central auditory gain (Noreña, 2011): because the input-output slope of the auditory nerve is usually decreased after hearing loss, the inputoutput slope of the chopper neurons of the ventral cochlear nucleus adapts itself to the new (decreased slope) input-output functions of cochlear nerve fibers (Cai et al., 2009). The steeper slope for the loudness functions (defining recruitment) could then be considered as a perceptual correlate of this adaptation of the central gain.

If loudness recruitment is a "normal" adaptation of central auditory gain to the reduced input from the auditory nerve and loudness growth curves are the perceptual correlate of this adaptation, our results argue in favor of a maladaptive central auditory gain in tinnitus, in both normal-hearing and hearingloss ears. The steepened loudness growth functions with and without threshold elevation are consistent with the prediction of the Zeng model of hyperacusis and thus support the maladaptive central auditory gain theory (Zeng, 2012). Note that the loudness growth in half-octave bands method (as described by Allen et al., 1990), by splitting the dynamic range into 15 equispaced levels, may decrease the number of data points at high sound levels. This factor, combined with the smaller number of ears in each of the hearing-loss categories, have contributed less statistical power in higher sound level categories.

\section{Conclusion}

We show increased sensitivity to sound (abnormal loudness growth) in individuals with tinnitus compared with individuals without tinnitus. The increased sensitivity was particularly pronounced in ears with normal audiograms, suggesting some "hidden" hearing loss. Overall, these results are consistent with the hypothesis that tinnitus and hyperacusis may both result from an increase of central gain. However, although current models suggest that auditory hypersensitivity should be restricted to the frequency range of the "tinnitus spectrum," our study challenges this prediction showing that hypersensitivity extends below the region of hearing loss.

\section{References}

Allen JB, Hall JL, Jeng PS (1990) Loudness growth in 1/2-octave bands (LGOB) - a procedure for the assessment of loudness. J Acoust Soc Am 88:745-753. CrossRef Medline

Al-Salim SC, Kopun JG, Neely ST, Jesteadt W, Stiegemann B, Gorga MP (2010) Reliability of categorical loudness scaling and its relation to threshold. Ear Hear 31:567-578. CrossRef Medline

Cai S, Ma WL, Young ED (2009) Encoding intensity in ventral cochlear nucleus following acoustic trauma: implications for loudness recruitment. J Assoc Res Otolaryngol 10:5-22. CrossRef Medline

Chrostowski M, Yang L, Wilson HR, Bruce IC, Becker S (2011) Can homeostatic plasticity in deafferented primary auditory cortex lead to travelling waves of excitation? J Comput Neurosci 30:279-299. CrossRef Medline

Clark JG (1981) Uses and abuses of hearing loss classification. ASHA 23: 493-500. Medline

Dauman R, Bouscau-Faure F (2005) Assessment and amelioration of hyperacusis in tinnitus patients. Acta Otolaryngol 125:503-509. Medline

Eggermont JJ, Roberts LE (2004) The neuroscience of tinnitus. Trends Neurosci 27:676-682. CrossRef Medline

Formby C, Gold SL (2002) Modification of loudness discomfort level: evidence for adaptive chronic auditory gain and its clinical relevance. Semin Hear 23:21-34. CrossRef

Formby C, Sherlock LP, Gold SL (2003) Adaptive plasticity of loudness induced by chronic attenuation and enhancement of the acoustic background. J Acoust Soc Am 114:55-58. CrossRef Medline

Fournier P, Hébert S (2012) Gap detection deficits in humans with tinnitus as assessed with the acoustic startle paradigm: does tinnitus fill in the gap? Hear Res. Advance online publication. Retrieved December 23, 2012. doi:10.1016/j.heares.2012.05.011. CrossRef Medline

Gu JW, Halpin CF, Nam EC, Levine RA, Melcher JR (2010) Tinnitus, diminished sound-level tolerance, and elevated auditory activity in humans with clinically normal hearing sensitivity. J Neurophysiol 104: 3361-3370. CrossRef Medline

Gu JW, Herrmann BS, Levine RA, Melcher JR (2012) Brainstem auditory evoked potentials suggest a role for the ventral cochlear nucleus in tinnitus. J Assoc Res Otolaryngol 13:819-833. CrossRef Medline

Hébert S, Carrier J (2007) Sleep complaints in elderly tinnitus patients: a controlled study. Ear Hear 28:649-655. CrossRef Medline

Hébert S, Paiement P, Lupien SJ (2004) A physiological correlate for the intolerance to both internal and external sounds. Hear Res 190:1-9. CrossRef Medline

Hébert S, Canlon B, Hasson D (2012) Emotional exhaustion as a predictor of tinnitus. Psychother Psychosom 81:324-326. CrossRef Medline

Heinz MG, Issa JB, Young ED (2005) Auditory-nerve rate responses are inconsistent with common hypotheses for the neural correlates of loudness recruitment. J Assoc Res Otolaryngol 6:91-105. CrossRef Medline

Joris PX (2009) Recruitment of neurons and loudness. Commentary on "Encoding intensity in ventral cochlear nucleus following acoustic trauma: implications for loudness recruitment" by Cai et al. J Assoc Res Otolaryngol 10:1-4. CrossRef Medline

Khalfa S, Dubal S, Veuillet E, Perez-Diaz F, Jouvent R, Collet L (2002) Psychometric normalization of a hyperacusis questionnaire. ORL J Otorhinolaryngol Relat Spec 64:436-442. CrossRef Medline

Kujawa SG, Liberman MC (2009) Adding insult to injury: cochlear nerve degeneration after "temporary" noise-induced hearing loss. J Neurosci 29:14077-14085. CrossRef Medline

Lin HW, Furman AC, Kujawa SG, Liberman MC (2011) Primary neural degeneration in the guinea pig cochlea after reversible noise-induced threshold shift. J Assoc Res Otolaryngol 12:605-616. CrossRef Medline

Moore BC, Glasberg BR, Hess RF, Birchall JP (1985) Effects of flanking noise bands on the rate of growth of loudness of tones in normal and recruiting ears. J Acoust Soc Am 77:1505-1513. CrossRef Medline

Munro KJ, Blount J (2009) Adaptive plasticity in brainstem of adult listeners following earplug-induced deprivation. J Acoust Soc Am 126:568571. CrossRef Medline

Norena A, Micheyl C, Chéry-Croze S, Collet L (2002) Psychoacoustic characterization of the tinnitus spectrum: implications for the underlying mechanisms of tinnitus. Audiol Neurootol 7:358-369. CrossRef Medline

Noreña AJ (2011) An integrative model of tinnitus based on a central gain controlling neural sensitivity. Neurosci Biobehav Rev 35:1089-1109. CrossRef Medline

Noreña AJ, Chery-Croze S (2007) Enriched acoustic environment rescales auditory sensitivity. Neuroreport 18:1251-1255. CrossRef Medline

Noreña AJ, Farley BJ (2012) Tinnitus-related neural activity: theories of generation, propagation, and centralization. Hear Res pii:S03785955(12)00246-8. CrossRef Medline

Penner MJ (1986) Magnitude estimation and the "paradoxical" loudness of tinnitus. J Speech Hear Res 29:407-412. Medline 
Reavis KM, Rothholtz VS, Tang Q, Carroll JA, Djalilian H, Zeng FG (2012) Temporary suppression of tinnitus by modulated sounds. J Assoc Res Otolaryngol 13:561-571. CrossRef Medline

Roberts LE, Moffat G, Baumann M, Ward LM, Bosnyak DJ (2008) Residual inhibition functions overlap tinnitus spectra and the region of auditory threshold shift. J Assoc Res Otolaryngol 9:417-435. CrossRef Medline

Schaette R, McAlpine D (2011) Tinnitus with a normal audiogram: physiological evidence for hidden hearing loss and computational model. J Neurosci 31:13452-13457. CrossRef Medline

Stillman JA, Zwislocki JJ, Zhang M, Cefaratti LK (1993) Intensity justnoticeable differences at equal-loudness levels in normal and pathological ears. J Acoust Soc Am 93:425-434. CrossRef Medline

Ward LM, Baumann M (2009) Measuring tinnitus loudness using con- strained psychophysical scaling. Am J Audiol 18:119-128. CrossRef Medline

Weisz N, Hartmann T, Dohrmann K, Schlee W, Norena A (2006) Highfrequency tinnitus without hearing loss does not mean absence of deafferentation. Hear Res 222:108-114. CrossRef Medline

Zeng FG (2012) An active loudness model suggesting tinnitus as increased central noise and hyperacusis as increased nonlinear gain. Hear Res. Advance online publication. Retrieved December 23, 2012. doi:10.1016/j.heares.2012.05.009. CrossRef Medline

Zhou X, Henin S, Long GR, Parra LC (2011) Impaired cochlear function correlates with the presence of tinnitus and its estimated spectral profile. Hear Res 277:107-116. CrossRef Medline 